Article

\title{
Destination Marketing Organizations and Climate Change-The Need for Leadership and Education
}

\section{Rachel Dodds}

Ted Rogers School of Hospitality \& Tourism Management, Ryerson University, 350 Victoria Street, Toronto, ON, M5B 2K3, Canada; E-Mail: r2dodds@ ryerson.ca; Tel.: +1-416-979-5000 Ext. 7227; Fax: +1-416-979-5281

Received: 8 October 2010; in revised form: 27 October 2010 / Accepted: 27 October 2010 / Published: 2 November 2010

Abstract: Destination Marketing Organizations (DMOs) operate at many levels ranging from the national to the municipal and have evolved over the years to respond to the geographical and political realities that are associated with tourism supply. Alongside providing information to potential visitors, DMOs work to make a destination attractive by showcasing its unique aspects and attractions. As the appeal of destinations, cost of doing business and the destination brand may be affected by the possible effects of climate change, this study aims to identify opportunities and threats to municipal and provincial/territorial DMOs and their members as well as identify measures they are undertaking to address the potential impacts. A study conducted of Canada's provincial and municipal large DMOs was conducted in 2009. This research found that awareness of climate change in Canada's tourism industry is increasing, but more efforts must be undertaken to mitigate climate change. To address climate change and tourism, this paper suggests doing three things: (a) DMOs need to demonstrate leadership about climate change education and mitigation to all their members; (b) government policy and action are needed to provide incentives for industry to address climate change; and (c) industry members require further education to take the steps necessary mitigate risk and to adapt. The internet has changed the DMOs' roles and how they provide information to the consumer; as such, they have been presented with an opportunity to take on new roles as educational and marketing providers. This paper will outline in the current shifts among Canadian DMOs and will discuss the key issues that are applicable to DMOs worldwide.

Keywords: destination marketing organizations; climate change; leadership; destination appeal 


\section{Introduction}

The global scope of the tourism industry and its reliance on the mobilization of almost one billion people each year make the industry an important contributor of greenhouse gases and to climate change. The World Economic Forum (WEF) estimates that the tourism sector is responsible for 5\% of global anthropogenic greenhouse gas emissions [1] Due to its size and dependence on its natural environment, tourism is particularly vulnerable to the impacts of climate change [2]. This study does not seek to detail or provide examples of specific climate scenarios but instead aims to understand opportunities and barriers facing tourism destinations with regard to climate change. Destination Marketing Organizations were the focus of this study as it is these organizations that represent much of a country's tourism product.

The Intergovernmental Panel on Climate Change (IPCC) defines climate change as

"... a change in the state of the climate that can be identified (e.g., using statistical tests) by changes in the mean and/or the variability of its properties, and that persists for an extended period, typically decades or longer. Climate change may be due to natural internal processes or external forcings, or to persistent anthropogenic changes in the composition of the atmosphere or in land use" [3].

Although there is a natural cycle of climate changes [4], the extreme changes that are now facing the planet are agreed to be directly related to the rapid technological advances and population growth in the last century [4]. The UNEP/UNWTO [2] attempts to quantify the links between tourism and climate change and concludes that carbon dioxide emissions from tourism activities (transport, accommodation, activities) account for an estimated 4-6\% of total emissions worldwide. If mitigation measures are not implemented, tourism's contribution to carbon dioxide emissions could grow by $150 \%$ in the next 30 years [5]. Arguably, if climate change is not properly addressed through adequate adaptive and or mitigation measures, it could lead to a shift in the attractiveness of destinations around the world [6-12]. While some locations could experience higher levels of attractiveness due to favourable temperatures, other destinations could become less appealing, causing a shift in visitation patterns [13]. The impacts of climate change on the tourism industry have been categorized into direct climatic impacts (e.g., redistribution of climatic assets among tourism regions), indirect environmental change impacts (e.g., water shortages, biodiversity loss), impacts of mitigation policies on tourist mobility (e.g., changes in tourism flows due to increased prices), and indirect societal changes (e.g., changes in economic growth) [5].

Destination Marketing Organizations (DMOs) are tasked with the role of marketing their region to travel consumers and travel trade intermediaries [14]. This study identifies the opportunities and challenges that climate change poses to Canada's tourism products in an urban as well as provincial setting. It then determines which DMOs have implemented initiatives to mitigate or adapt to impacts of climate change. Lastly, this study identifies barriers and incentives necessary to influence the tourism industry in Canada's different regions to increase their level of participation in addressing effects of climate change. This paper will argue that although some DMOs have undertaken voluntary efforts to address climate change, leadership and education is absent and national legislation is needed if climate change is to be addressed in the tourism industry. 


\subsection{Climate Change and Tourism-A Canadian Context}

Tourism is one of the leading growth sectors in Canada. Approximately 30 million non-resident travellers entered Canada in 2007-as well as approximately 34 million Canadians travelling within the country. Business and leisure travellers (both international and domestic) spent a total of $\$ 70.6$ billion in Canada in 2007 alone [15]. Foreign travellers account for $23 \%$ of total Canadian tourism expenditures, making tourism an important export industry $[15,16]$. The impacts of climate change may positively affect Canada's key tourism product especially with references to the recreational and nature-based tourism industry in Canada [17]. Warm weather outdoor recreational activities such as summer festivals, campgrounds, golfing, and public beach access could experience benefits from the longer operating seasons [12,18,19]. Conversely, winter recreation activities may be negatively affected, which may result in a decline or elimination of sports such as skiing, snowmobiling, or tourism related events such as winter festivals $[17,18]$. For example, the Canadian Rocky Mountains experienced a $25 \%$ decrease in glacier coverage in the 20th century [17].

"Many of the species that Canada features in its tourism marketing (whales, otters, caribou, polar bears) are already endangered, and rapid changes in their habitat increase the risk of their extinction. Habitat changes such as the warming of Canada's boreal forest is encouraging the spread of new pests and diseases such as the pine beetle which reduce valuable timber inventories and blight the landscape and aesthetics sought by visitors" ([9], p. 41).

As increasing studies about tourism and climate change outline [7,8,20-23], tourism will be affected and efforts are increasingly needed to curtail negative impacts. There are two measures within tourism that are used to address climate change: mitigation and adaptation. Mitigation usually refers to reducing greenhouse gas emissions so as to lessen the impact of tourism on climate change whereas adaptation refers to adapting or modifying actions or activities to adjust to a changing climate. Within a destination context, many tourism operations and organizations rely on marketing their offerings through a DMO, whether they are urban or rural based. Understanding what DMOs perceive climate change issues to be and the efforts they are taking to address such issues may provide some insight into climate change mitigation and adaption.

\subsection{Destination Marketing Organizations}

DMOs promote their regions with the intent of increasing tourism to the destination or improving its public image [24]. Most DMOs in Canada are private, not-for-profit industry associations with an independent board of directors. DMOs bridge various sectors within the tourism industry including: hotels, B\&Bs, airlines and ground transit, attractions, tour operators, travel agents, convention facilitators, retail operators and restaurants. Funding for DMOs come from a combination of public funding and revenues generated through membership and service charges. Many Canadian municipalities have sought to increase their tourism revenue by establishing DMOs to market their region to travellers and travel trade intermediates (e.g., travel agencies). In some municipalities, hotels can voluntarily charge a Destination Marketing Fee on hotel rooms, which is then channelled back to the DMO. Traditionally services provided by DMOs include promotional and advertising campaigns, publishing and distributing visitors' guides, online marketing, training, research and product 
development. One crucial market communication channel for DMOs has been the Internet, as information technology (IT) has transformed the tourism industry into a digital economy [25]. Although the integration of IT into the fabric of a DMOs overall marketing strategy is considered as an important key to success [26], the exponential explosion of information online has presented the DMOs with increasing challenges as well as opportunities in the information era. DMOs are challenged because of threats in their external environments such as the increased use of technology, changes in the industry's structure and market changes [26]. Additionally, many potential customers use alternative internet sources to find information about the destination, thereby challenging DMOs to provide relevant, added-value information which differentiates them from these alternative sources.

As there is little action on climate change within Canada by the government to mitigate or adapt at this time, DMOs could be uniquely situated to address the issues of climate change in the tourism industry. DMOs link the interests of the tourism industry to government policy-makers and consumer demand. DMOs are also equipped to identify shifts in the marketplace such as increased demand for climate-friendly tourism options, and provide guidance and education for industry to meet the demands of new climate change legislation. Due to this context, this research sought to identify the current level of awareness, and efforts to address climate change by DMOs and/or their members. A number of Canadian DMOs are located in urban centres as it is these regions that serve as transportation hubs for travellers en route to other parts of the surrounding area, including rural and protected areas. In Canada there are 10 provinces and 3 territories and the country offers a wide diversity of products ranging from ocean activities (whale watching, boating, surfing) on the east and west coasts to urban and natural attractions (wildlife viewing, provincial and national park activities, outdoor experiences, urban attractions) in the interior and arctic areas. Although there are other smaller DMOs that provide information about rural areas, the larger municipal DMOs offer the widest range of products that include activities beyond the urban experience. For example, Tourism Calgary located in western Canada offers information on activities and attractions in both the Banff and Jasper parks as well as tour experiences in the prairie areas. Tourism Halifax, located on the east coast, has members from many different areas of the Province of Nova Scotia including rafting companies and hiking tours that are located outside Halifax's urban area. The provinces also have DMOs which market the entire province or territory. Provinces and large municipalities were contacted for this study to gauge the widest area for study.

\section{Methodology}

This research sought to explore the current issues and opportunities for climate change and tourism from large municipalities and provincial/territorial DMOs perspectives. As DMOs often play an educational role as well as providing access to markets for its members, this research sought to understand the differing views across a country which has a large geographical area and is facing many different issues that are the result of climate change. Qualitative research was used in this study as it is based on the premise that social actors create emergent social processes and power structures which may refer to common patterns in social interactions [27]. This research is qualitative in nature, as there is no "formal" hypothesis to be tested [28]. This research is also inductive and interpretive, and in order to determine patterns, the following general questions were assessed including: 
- challenges DMOs were facing as a result of climate change;

- mitigation / adaptation strategies;

- barriers or issues hindering the implementation of mitigation strategies;

- perceptions of demand by travellers for more sustainable forms of tourism; and

- tools and incentives needed to address climate change.

A full list of questions is outlined at the end of this paper.

This research compares the opinions of large municipal DMOs across Canada as well as territory and provincial DMOs. Although there are many levels of DMOs, large municipal DMOs were chosen in order to ensure that Canada's largest areas of Canada's tourism product were represented. Large municipal DMOs were also chosen for this study because much of Canada's tourism product is accessible through these municipal gateways including hotels, tour operators, attractions and events. As most visitors access Canada through municipal gateways, these DMOs often represent products that are located in national parks and other fragile areas as these members gain increased market access. Table 1 outlines the municipalities represented. A 70\% response rate was obtained (19 of 27 DMOs who were contacted for this survey responded). Equal representation from across Canada was gained.

Table 1. Municipal DMOs Interviews and geographic location.

\begin{tabular}{|l|l|}
\hline \multicolumn{2}{|l|}{ DMOs } \\
\hline West Coast: & Vancouver \\
\hline Prairies: & Saskatoon, Winnipeg \\
\hline Rockies: & Calgary, Edmonton \\
\hline Central: & Montreal, Toronto, Ottawa, Quebec City \\
\hline Eastern: & Halifax \\
\hline Northern/Arctic: & Whitehorse \\
\hline Provinces/Territories: & $\begin{array}{l}\text { Northwest Territories, Nunavut, Ontario, } \\
\text { Manitoba, British Columbia, Nova Scotia, } \\
\text { Prince Edward Island }\end{array}$ \\
\hline
\end{tabular}

Data were collected through semi-structured interviews. The measure was reliable as all interviewees were asked the same 17 questions with questions provided in advance to help avoid interviewer bias and interviews were conducted with CEO's to ensure data reliability. Informed and written consent was obtained from each respondent. Data collection took place in 2009. Due to the large geographic area, telephone interviews were conducted and were between one to two hours in length. Responses were then coded using 'latent coding' [29] and responses grouped together to form themes. It should be noted that there are some discrepancies between what is said by the interviewees and scientific facts, as respondents were not climate change experts, however their viewpoints are representative of industry and provide key insights into issues pertaining to mitigation and policy development in this area. 


\section{Results}

\subsection{Impacts and Challenges of Climate Change}

Respondents were first asked to rate the importance of climate change on the future viability of the tourism industry on a scale of 1 to 10 , with 10 indicating extreme importance. This question was asked on a global context to gain an understanding of the interviewees' overall concern. Most respondents agreed that climate change was a very important factor in tourism's future viability (mean response: 7.8 ). Respondents were then prompted to discuss specific issues in relation to their geographical area.

Most of the respondents (located on the west and east coast and northern geographical areas) believed that climate change was extremely important ( 9 or 10/10) to the future viability of the tourism industry. Conversely, two respondents (located in the central Prairies) believed that climate change was of low importance (mean 5/10). These results may suggest a geographic divide in attitudes regarding climate change especially since, currently, most climate change impacts have been felt in coastal and arctic areas. Generally, respondents who identified climate change as extremely important also showed a heightened awareness of the impacts of climate change and identified environmental-sensitivity in their regions such as habitat and biodiversity loss

Respondents who did not consider climate change an important factor in the future viability of tourism believed existing research on climate change was not conclusive enough to change tourists' habits. One respondent expressed scepticism about existing science, "it's too early to tell the true effects of climate change on weather patterns and environment." Another respondent believed that climate change will not have a "dramatic impact on people visiting different parts of Canada and beyond" because people are "reluctant to give up leisure travel opportunities." This respondent represented a geographical area which has not felt many impacts from climatic change.

Respondents also identified a variety threats posed by climate change to the tourism industry. Responses were consistent with previous studies outlining impacts $[13,30]$ such as unpredictable weather patterns and the impact on seasonal tourism, in particular on winter tourism. Changing weather patterns also posed a threat to infrastructure. One respondent noted that their municipality could not support an increase in summer tourism large enough to offset losses to winter tourism. Disease epidemics were a cited as a potential threat by one respondent (such as the impact of the SARS outbreak on Toronto's tourism industry in 2002). In some instances, respondents identified specific tourist attractions that were threatened by climate change. Arctic regions claimed that there are more overcast days which threaten tourism driven by the Aurora Borealis. Eastern Canadian areas saw increasing ice rain as a threat to winter festivals, and East Coast areas expressed concern about rising sea levels in coastal communities.

Several respondents felt the challenge posed by climate change on the tourism industry was a lack of awareness and action both within the industry and government and among consumers. Concerns included that there was still a lack of clarity on the issue of climate change, funding was not available to make necessary changes and there was a lack of knowledge of best practices to mitigate or adapt to impacts. One respondent felt that greatest threat was to ignore climate change until the impacts become unmanageable. In some cases, efforts to mitigate or adapt to climate change were seen as a threat to the industry. One municipality was concerned that businesses would cut travel to reduce their carbon 
footprint which could disrupt the convention and festivals/events sector. Respondents also identified potential regulation of the airline industry and the costs that would be incurred to meet those regulations as a major threat. At the time of the survey, a recession and economic crisis was weighing heavily upon the tourism industry. Several respondents saw the economic crisis as a major threat because businesses were struggling to make profits and therefore were less inclined to adopt mitigation strategies that might require an investment of capital.

\subsection{Opportunities for Canadian Tourism Industry}

Respondents were then asked to identify potential opportunities for the Canadian tourism industry with regard to climate change. The two most commonly cited opportunities were the potential advantages of warmer weather (as Canada has historically been a colder weather climate) and the potential for Canada to leverage itself as an environment-friendly tourism destination. Respondents felt that Canada's tourism industry was less susceptible to climate change than other nations, and Canada could become a more appealing destination as such. As temperatures become warmer, potential for new tourism opportunities could develop. Some felt that the northern region would benefit economically from the opening of the Northwest Passage. One respondent noted: "Many times we see people from the United States come... because there is sometimes no longer snow in the Northeast part of the United States." There were several other opportunities identified by respondents. One DMO suggested that Canada has a strong climate research infrastructure in place, and Canadian tourism could benefit from being on the forefront of scientific research. Another saw the issue of climate change as an opportunity to educate and motivate consumers and business to adopt more sustainable habits and practices. Interestingly DMOs did not discuss their role in helping their members.

\subsection{Respondents' Perception of Consumer Attitudes}

All respondents agreed that consumers are more aware of the impact of climate change than in the past. Increasingly, travellers are inquiring about environmental practices. However, most respondents felt consumers are not changing their behaviours as quickly their perceptions, and that consumers are not well-informed enough to make the right behavioural changes. This is consistent with other studies $[20,31,32]$.

Respondents expressed concern about travellers' willingness to pay a premium for environmentally-friendly practices. One DMO noted a 2007 Lonely Planet study that concluded 93 percent of tourists would prefer to travel to destinations with environmentally friendly practices, however, another suggested there is still reluctance to assume the additional expense. Most respondents believe there is a market for environmentally-friendly tourism although it is still seen as a niche market that is susceptible to economic factors. The industry wants to see returns on their investment in green initiatives, but there is scepticism about the level of consumer demand. At the present, DMOs see the business incentive for green initiatives as a 'tie-breaker' that could provide competitive advantage when travellers must choose between destinations. Respondents did, however, note that the product which many visitors come to see are their members and therefore research is needed about consumer demand. 


\subsection{Initiatives Undertaken by DMOs}

The interviews then investigated ways DMOs had taken action to mitigate or adapt to impacts on climate change. This question was phrased as both internal measures and also as actions taken to reach out to members. Most respondents had not taken any concrete actions as they noted that their role was to market a destination, not be a climate change expert. A few (three) respondents had taken no actions to reduce their impact while some respondents have instituted measures such as carbon offsetting for travel and member education programs (those located in the arctic or coastal areas).

Internally, activities that DMOs were introducing included setting up green teams and environmental policies to reduce impacts, however this was not necessarily in response to climate change pressures or impacts specifically. DMOs have also produced and distributed literature to members detailing best practices for reducing environmental impacts. When asked if the respondent organizations were sufficiently well briefed on the topic of climate change to develop internal policies and action, half of the respondents felt they were not sufficiently informed. Three respondents felt that it was not the priority of a DMO to develop environmental policies and that the task should be left to government regulatory agencies.

There were a few specific actions that were taking place. One DMO is currently undergoing an audit of members' practices to determine their next course of action and to assess who is doing what sustainably. Another DMO undertook a survey of members to determine which had instituted their own environmental policy - however, again this was not directly related to climate change. Roughly half had a written policy in place for sustainability or environmental management but none were specifically climate change policies. DMOs representing Canada's three largest municipalities (Toronto, Vancouver, and Montreal) have introduced carbon offsetting for employee travel. Several other respondents are currently investigating carbon offsetting as a future option. Only one respondent rejected carbon offsetting as an option: "I don't think we really believe in it. My personal belief is that it stops countries from cleaning up their act." Some DMOs have initiated research on the impacts caused by members and interviewees did outline efforts done by some of their members on mitigation and adaption, however, it was limited.

Some DMOs outlined member practices such as hotels or attractions obtaining LEED certification and energy reduction measures by accommodations and transport providers. These were few in nature.

\subsection{Barriers to Implementing Initiatives}

Respondents were then asked to identify barriers to implementing initiatives. The most commonly identified barriers were economics and a lack of policy or incentives for the DMOs to make efforts (half of respondents). Education and economics were seen as interrelated, and a combination of both was needed to overcome technical barriers. Half of respondents identified economic challenges as the dominant a barrier to implementing initiatives both internally and for their members. At the time of the survey the global financial crisis and recession were greatly impacting the tourism industry. Several respondents noted that the economic crisis could hamper progress toward achieving environmental goals. With money in short supply, businesses were focusing their resources on the best returns-on-investment. Several DMOs viewed green tourism as a niche market, and a less immediate 
concern. One respondent noted: “...climate change is what I term a 'luxury issue'. When we have time, we'll move forward and deal with it."

One third of respondents also identified lack of education as a major barrier to implementing initiatives. Ways in which respondents defined education varied. Some respondents felt that there needed to be more education to the public, while others felt that industry needed more educational resources on the issue of climate change. Respondents wanted information on best practices from reliable sources such as government organizations or scientific bodies and all DMOs noted that they felt that there was a lack of action due to non-existent policies or leadership from government. They also wanted to know about effective strategies that have been implemented by other businesses and industries. Respondents wanted specific return on investment information for climate friendly practices and information on the business incentive for implementing initiatives. Specifically, they wanted to know what the market for green tourism is, and how to communicate effectively with them.

The technical barrier often cited was the lack of professional expertise on the issue among DMO personnel. DMOs are chiefly marketing organizations, and they often lack the skills set or resources to dedicate to environmental initiatives. This technical barrier could be overcome by an investment in personnel or through educational programs. Investing in personnel has its own difficulties. As membership organizations, DMOs are accountable to the demands of their members. One DMO noted "I can go to people in our office and say you should focus more on selling (us) as a green destination, but they are driven by what the clients are asking for. And, if the client is not asking for it, then they're not going to provide it." As with previous responses, many respondents discussed general issues of environmental management interchangeably with mitigation efforts while there was no real discussion of adaptation.

\subsection{Strategies and Solutions for Adaptation and Mitigation of Climate Change Effects}

DMOs were asked what actions would be most helpful to support tourism suppliers in Canada with respect to climate change. Again, coastal, mountain and northern DMOs were the most forthcoming with solutions as it is these regions of the country which have to date, experienced the greatest negative impacts. Regulatory incentives such as tax rebates for operations that achieve benchmarks, or penalties for organizations that fail to comply with standards were the most popular response. Education, communication, access to research and information sharing once again factored into responses, as did the need to establish a standardized certification body to set industry benchmarks. Most DMOs, regardless of location, said that industry is looking to the government for guidance on climate change initiatives. Respondents commonly expressed a desire for accurate information and standardization from the government. The respondents believed business will act more quickly where there is a financial or legal motivation. Respondents suggested most commonly that regulatory incentives should be introduced to the industry.

"Whether it is a positive tax treatment, or investment capital, or whatever the case may be, that gets business to change their practices. The other approach is penalize them, individuals or business for bad practices, but either way it comes down to monetary decisions. "Ultimately, you need regulation on [tourism suppliers]. You need people to be forced into doing it." 
Respondents also wanted a standardized certifying body to police the industry and provide consumers with accurate information. Respondents point to several green certifications that are of varying quality and questionable value and currently none relates to Canada specifically. It was thought that an industry standard could more effectively hold businesses accountable for their claims and provide an effective marketing tool.

\section{Discussion}

Although this study was on Canada, DMOs from around the world should take heed. As public-private partnerships, DMOs represent the varied interests of many tourist sectors within their geographic region, and therefore they are keenly aware of the impacts wrought by changes in the regional marketplace, and by policy changes on their client organizations. DMOs are also positioned well to assess the threats posed by climate change on their region as they represent a large number of varied tourism attractions and offerings to a diverse audience. This research found, however, that DMOs are not taking a leadership role in addressing impacts, or educating its members about climate change as they primarily see themselves as a marketing agency and are focusing on short term promotional issues rather than long term competitiveness.

This research supports previous research $[31,33,34]$ in that there is a lack of knowledge by the consumer and industry. DMOs noted that although they see an increased interest by consumers in environmental travel, most respondents felt consumers are not changing their behaviours as quickly as their perceptions, and that consumers are not well-informed enough to demand more sustainable options. Most respondents see the link between their behaviour and climate change and some efforts have been made to limit environmental impacts although these are preliminary and not necessarily specifically focused on climate change. As DMOs' primary focus is on marketing and value for their membership fees, a short term return on investment was seen to be a key issue. Although much research $[7,19,20]$ has demonstrated the longer term impacts of climate change (especially to mountain, arctic and coastal regions), DMOs and many of their members are not considering the longer term impacts. Clearly there is a need for more education for both the industry and the consumer. If both consumers and industry are informed on the issues of climate change, consumer demand for green initiatives will likely increase and the industry will be prepared with the necessary tools and knowledge to meet that demand. Furthermore, as regulation is instituted, industry will need to know how to meet regulatory requirements in a cost effective way. Despite this need, there has been little pressure placed on the industry by the government to implement climate change initiatives. The result, therefore, is a piecemeal approach to climate change mitigation and adaption. From this research, it was clear that it should be the role of federal government to lead the movement toward climate change action by developing a comprehensive climate change strategy related to tourism and assisting the industry in developing and implementing adaptation and mitigation strategies.

DMOs in different parts of Canada have different thoughts towards the severity of climate change. This is not surprising due to the vast geographical area and the many different climatic regions that the country encompasses. This research found that, although there are some opportunities for the Canadian industry to take advantage of the positive impending climate changes (increased seasonality, new areas opening up for nature based tourism and the consumers demand for destinations and companies which 
are seen to be taken a positive stance), most initiatives to counter or adapt to the negative aspects (movement to alternative forms of energy, education, planning, etc.) are voluntary and few in number. Although climate change is becoming an increasingly important issue to the majority of DMOs interviewed, there is little climate change action and interviewees in all geographic regions are looking to government for guidance. Some authors state that regulation [20,34] and policy initiatives are the answer to regulating emissions and adapting to climate change impacts and this research agrees with such findings. As per responses from DMOs, unless Canada accepts politically its responsibility for reaching Kyoto, regulation in the tourism sector is highly unlikely as tourism is intrinsically linked to other economic sectors. There is a need for partnerships between government and industry to foster knowledge sharing, however, government must take a leadership role to ensure regulations are set and the tourism industry reaches its needed targets for GHG reduction [9].

\section{Conclusions}

Changing weather patterns make seasons less predictable, threatening the sustainability and viability of tourism sectors across the nation. Tourism also contributes to climate change and environmental degradation, effectively undermining the environments that are its most vital resource. Consumer awareness on the issue of climate change has had a limited impact on the tourism industry, but is likely to increase even more as education continues to be a key focus of climate change mitigation practices. It is essential that the very body that attracts the consumer and promotes the product - the DMO-stays on top of the challenges which affect it. This research looked at DMOs views and actions about climate change as DMOs market and represent much Canada's tourism product. Because of this role, it was thought that they could be uniquely situated to act as educators to their client-members on the issue of climate change, and as information providers to planners for future threats to the industry. This was not the case. In Canada, although climate change is becoming an increasingly important issue to many DMOs and their members, there is little action for climate change mitigation or adaptation.

As DMOs situate themselves between public and the private interests, having both concern for the prosperity and sustainability of their industry and the region as a whole, it was thought that they could be instrumental in communicating the need to mitigate and adapt the effects of climate change to a broad group of stakeholders. The respondents, however, felt they did not have the resources to provide adequate training and planning for climate change mitigation. A critical issue for mitigating the effects of climate change is that a holistic and communicative approach that balances tourism development with other activities is necessary as it is difficult to regulate climate change and tourism as a separate function from other issues. This research concludes that the following action be undertaken to further this agenda:

- Improve DMO education and awareness of climate change and provide them with the tools and best practices needed to measure impacts

○ Establish incentives for the industry to achieve environmental benchmarks and to adopt sustainability measures

- Enforce accountable industry-wide standards to reduce environmental impacts caused by industry 
- Educate consumers of the impacts of their travels on their host destinations to foster demand

- Devise regional plans for the adaptation of the tourism industry to climate change impacts

The responses provided by the DMOs for this research illustrate a clear need for more communicative and policy-based action with regard to mitigating the effects of climate change. The DMOs from this study note that they and the industry are looking to the government for guidance. Currently in Canada, policy does not seem to be forthcoming. If industry is going to shift, there must be more regulatory benchmarks to get the industry to understand their current situation and to respond. Voluntary benchmarks have been set by some industry leaders, but economic factors and the competitive marketplace constrain wider action. For actions to occur, an overarching jurisdictional body that enforces adherence to benchmarks industry-wide is preferable to voluntary benchmarks. At the time of writing, a nationwide certification scheme was being proposed and piloted in Canada, however, voluntary, often market-driven, benchmarks may appeal to the eco-conscious traveler, but there is concern about the long-term viability of this market.

DMOs are recognizing an increase in consumer demand for operators who offer environmentallyfriendly practices, but these consumers are still considered a niche market, being too small a proportion of the overall marketplace to provide a sustainable industry. As environmental education increases, more consumers are likely to demand that tourism operators adopt responsible methods which may have a positive effect on mitigating climate change. DMOs see the potential for eco-friendly travel as a short term opportunity for market differentiation and this may offer some incentive.

DMOs could function as long-term planning entities within regions. Businesses within the tourism industry are seen as being oriented toward short-term sustainability and this may have been further exacerbated by the recent global financial crisis. Though DMOs are chiefly marketing organizations, they have the potential to recognize and respond to the impacts of climate change in their regions. In some regions, the effects of climate change have already been experienced. In other regions, the effects are eminent. DMOs face increasing competition from other community-based or industry organizations that provide marketing services. For example, global events, individual websites or social media venues are often perceived as more relevant to inform the individual or organization about tourism options in a destination. As more people 'experience' a place, more focus will be put upon the attractiveness of a destination. As DMOs are feeling the squeeze from other forms of technology being used as a promotional tool and other impacts, education and leadership regarding climate change could become an added value proposition that they could offer their members. The DMO must be aware of how these issues affect their region, and prepare their members to adapt.

While this case study was Canadian, implications for DMOs in other regions can be applied. It is clear that DMOs in northern regions will feel different affects from those in the South, and that destinations in the deserts and prairies will have different impacts from those on the coasts, arctic areas and in mountainous regions. For DMOs to serve as effective educators, they need access to adaptation and mitigation strategies and incentives that are considerate of their regions, while also having awareness about climate change on a global perspective. This research found that DMOs as marketing and educational bodies do little to work with their client members about climate change impacts. 
It is important to note that the very nature of climate change is linked to a bigger issue - the dependency of tourism on a declining supply of natural resources. Without longer term strategic planning, the tourism industry in Canada and destinations globally, will not be equipped to deal with a changing future. The long-term, global threat of climate change affects all industries including tourism but until its effects are directly felt in terms of human life or prosperity, little will likely be done. Perhaps only when higher operating costs due to the cost of carbon, adapting to negative consequences such as snow making or flood defence systems or rising sea levels will changes be made. When destinations see reduced consumer demand as behaviour shifts towards sustainable tourism options, and brand images are negatively affected when evaluated on their sustainability credentials, will destinations react. Unfortunately, the tourism industry's lack of proactive measures may result in all the above - and these consequences will be hard to reverse. As public-private partnerships, DMOs could be uniquely positioned to undertake a role as educators, unfortunately they claim they are not equipped with the technology, finances or the knowledge to address these issues at the present time. If tourism is to move forward in this changing environment, something must be adjusted. Tourism is faced with two options. First, more effort is needed to provide industry with the necessary tools to transform their product into climate-friendly attractions-perhaps through auditing and/or improving environmental practices. Second, DMOs themselves need to realize that their very competitive position depends on adapting and changing for the future or they may soon become obsolete.

This study looked specifically at the Canadian industry but the issue of climate change is global in nature. Further research to assess the ways other municipal marketing organizations have responded to the issue of climate change could provide insight into effective methods employed elsewhere and spur further awareness of the issue to the wider field of marketing organizations.

\section{References and Notes}

1. WEF. Towards a Low Carbon Travel \& Tourism Sector. Available online: http://www.weforum. org/pdf/ip/att/ClimateChangeReportCopenhagen.pdf (accessed on 19 September 2009).

2. UNEP/UNWTO. Climate Change and Tourism: Responding to Global Challenges. Available online: http://www.unwto.org/sdt/news/en/pdf/climate2008.pdf (accessed on 10 August 2008).

3. IPCC. Annex 1: Glossary. Available online: http://www.ipcc.ch/pdf/glossary/ar4-wg3.pdf (accessed on 16 September 2009).

4. Climate Change 2007: Mitigation of Climate Change; Contribution of Working Group III to the Fourth Assessment Report of the Intergovernmental Panel on Climate Change; Cambridge University Press: Cambridge, UK, 2007.

5. UNWTO. UNWTO World Tourism Barometer, 2008. Available online: http://www.worldtourism.org/facts/wtb.html (accessed on 17 September 2009).

6. Dodds, R.; Kelman, I. How climate change is considered in sustainable tourism policies: A case of the Mediterranean Islands of Malta and Mallorca. Tourism Rev. Int. 2008, 12, 57-70.

7. Gössling, S. Global environmental consequences of tourism. Global Environ. Change 2002, 12, 283-302.

8. Gössling, S.; Hall, C.M. Uncertainties in predicting tourist flows under scenarios of climate change. Climatic Change 2006, 79, 163-173. 
9. Dodds, R.; Graci, S. Canada's tourism industry-Mitigating the effects of climate change: A lot of concern but little action. Tourism Hospit. Plann. Dev. 2009, 6, 39-51.

10. Peeters, P. Mitigating tourism's contribution to climate change-An introduction. In Tourism and Climate Change Mitigation Methods, Greenhouse Gas Reductions and Policies; Peeters, P.M., Ed.; Stichting NHTV Breda: Breda, The Netherlands, 2007; pp. 11-26.

11. Perry, A. Impacts of climate change on tourism in the Mediterranean: Adaptive responses. In Climate Change in the Mediterranean: Socio-Economic Perspectives of Impacts, Vulnerability and Adaptation; Giupponi, C., Shechter, M., Eds.; Edward Elgar Publishing: Cheltenham, UK, 2003; pp. 279-289.

12. Scott, D.; McBoyle, G.; Schwartzentruber, M. Climate change and the distribution of climatic resources for tourism in North America. Climate Res. 2004, 27, 105-117.

13. Amelung, B.; Nicholls, S.; Viner, D. Implications of global climate change for tourism flows and seasonality. J. Travel Res. 2007, 45, 285-296.

14. Choi, S.; Lehto, X.L.; Oleary, J. What does the consumer want from a DMO website? A study of US and Canadian tourists' perspectives. Int. J. Tourism Res. 2007, 9, 59-72.

15. TIAC/AITC (Tourism Industry Association of Canada). Tourism Facts, 2009. Available online: http://www.tiac.travel (accessed on 15 December 2009).

16. CTC. Facts and Figures Year Review. Available online: http://www.corporate.canada.travel/docs/ research_and_statistics/stats_and_figures/tourism_year-in-review_2006_web_eng.pdf (accessed on 26 January 2008).

17. Scott, D.; Jones, B. Climate Change \& Nature-Based Tourism: Implications for Park Visitation in Canada; Department of Geography, University of Waterloo: Waterloo, Canada, 2006.

18. Scott, D.; Jones, B.; Abi Khaled, H. The Vulnerability of Tourism in the National Capital Region to Climate Change; Technical Report to the Government of Canada's Climate Change Action Fund; University of Waterloo: Waterloo, Canada, 2005.

19. Scott, D.; Jones, B.; Lemieux, C.; McBoyle, G.; Mills, B.; Svenson, S.; Wall, G. The Vulnerability of Winter Recreation to Climate Change in Ontario's Lakelands Tourism Region; University of Waterloo: Waterloo, Canada, 2002; Department of Geography Publication Series Occasional Paper 18.

20. Becken, S.; Hay, J.E. Tourism and Climate Change: Risks and Opportunities; Channel View Publications: Bristol, UK, 2007.

21. Tourism, Recreation and Climate Change; Hall, C.M., Higman, J., Eds.; Channel View Publications: Bristol, UK, 2005.

22. Nicholls, S. Climate change, tourism and outdoor recreation in Europe. Manag. Leisure 2006, 11, 151-163.

23. Patterson, T.; Bastianoni, S.; Simpson, M. Tourism and climate change: Two-way street, or vicious/virtuous circle? J. Sustain. Tourism 2006, 14, 339-348.

24. Morrison, A.M. Hospitality and Travel Marketing, 3rd ed.; Delmar: Albany, NY, USA, 1998.

25. Buhalis, D. Tourism in an era of information technology. In Tourism in the Twenty-First Century; Faulkner, B., Moscardo, G., Laws, E., Eds.; Continuum: New York, NY, USA, 2000; pp. 163-180.

26. Gretzel, U.; Yuan, Y.; Fesenmaier, D. Preparing for the new economy: Advertising strategies and change in destination marketing. J. Travel Res. 2000, 39, 146-156. 
27. Warren, C.A.B.; Karner, T.X. Discovering Qualitative Methods; Oxford University Press: New York, NY, USA, 2010.

28. Patton, M. Qualitative Evaluation and Research Methods, 2nd ed.; Sage Publications: Thousand Oaks, CA, USA, 1990.

29. Neuman, W.L.; Robson, K. Basics of Social Research; Pearson: Toronto, Canada, 2009.

30. Wolfsegger, C.; Gössling, S.; Scott, D. Climate change risk appraisal in the Austrian ski industry. Tourism Rev. Int. 2008, 12, 13-23

31. Dodds, R.; Leung, M.; Smith, W. Assessing awareness of carbon offsetting by travellers and travel agents. Anatolia 2008, 19, 135-147.

32. Scott, D.; Jones, B.; Konopek, J. Exploring potential visitor response to climate-induced environmental changes in Canada's Rocky Mountain National Parks. Tourism Rev. Int. 2008, 12, 43-56.

33. Becken, S. How tourists and tourism experts perceive climate change and carbon-offsetting schemes. J. Sustain. Tourism 2004, 12, 332-345.

34. Gössling, S.; Broderick, J.; Upham, P.; Ceron, J.P.; Peeters, P.; Strasdas, W. Voluntary carbon offsetting schemes for aviation: Efficiency, credibility and sustainable tourism. J. Sustain. Tourism 2007, 1, 223-248.

\section{Appendix-Interview Questions for DMOs}

1. On a scale of $1-10$, how important do you consider climate change to be in determining the future viability of Canada's tourism industry? (with 10 indicating "of extreme importance") and why?

2. What are the major threats and challenges associated with climate change and tourism?

3. Where do you see opportunities for Canada's tourism industry with regard to climate change?

4. What action is your organization taking to address this issue? If so, please explain in detail (e.g., developing policies, introducing education programs, certification, carbon calculators and offsets etc.). If none, Q 5.

5. What action are you considering?

6. Is your organization is sufficiently well briefed on the topic to develop an internal policy and or action program? If not, what information would be most useful to you?

7. What other factors currently limit or prevent your organisation from taking action in response to climate change? (policy/technical/economic/other barriers)

8. What do you consider should be the role of the federal government in general and provinces in particular with respect to climate change?

9. What would most encourage your organization to develop policy/action for climate change in relation to tourism? What support, guidance, tools, skills and incentives would be most helpful to your organisation?

10. In your opinion, what actions would be most helpful to support tourism suppliers in Canada with respect to climate change?

11. Do you think consumer perceptions and behaviours are changing in regards to climate change and tourism in Canada? 
12. Do you have an internal carbon neutral procurement policy or initiative? If not, are you considering one for your organization?

13. Have you endeavoured to estimate the proportion of greenhouse gases contributed by tourism in your (province, city, sector) to Canada's overall emissions? Are you aware of any research that would provide a basis for such an estimate?

14. What other tourism destinations are doing a better job in response to climate change and, if you are aware of any, what action impresses you?

15. Are there positive examples and role models in other sectors (both Canadian and international) that you think could be useful exemplars for the Canadian tourism industry?

16. Do you know of any reports or studies about the future impact of climate change on the tourism industry in Canada in terms of product, operations, consumer behaviour and perceptions?

17. Do you have any further thoughts, suggestions to add to this issue that you would like to convey?

(C) 2010 by the authors; licensee MDPI, Basel, Switzerland. This article is an open access article distributed under the terms and conditions of the Creative Commons Attribution license (http://creativecommons.org/licenses/by/3.0/). 